\title{
Virtual Learning: Challenges and Coping Mechanisms of Language Learners in Rural Areas
}

\author{
Rizalin A. Francisco \\ Western Mindanao State University, Zamboanga City, Philippines \\ Corresponding Author: Rizalin A. Francisco, E-mail: rizalinfrancisco416@gmail.com
}

\author{
ARTICLE INFO \\ Received: August 11, 2021 \\ Accepted: September 04, 2021 \\ Volume: 1 \\ Issue: 1 \\ DOI: $10.32996 /$ jlds.2021.1.1.59
}

\section{KEYWORDS}

Online-based learning, challenges, coping mechanisms, rural area, language learners

\section{ABSTRACT}

The sudden shift from face-to-face instruction to online-based learning was prompted by the urgent necessity to continue the delivery of instruction amidst the COVID outbreak. Since all the country's institutions have opted to close schools and universities, students in both urban cities and rural towns have had to adjust to the new standard. Hence, this research study employed a descriptive-qualitative research design and conducted in-depth interviews to determine the challenges and coping mechanisms of language learners studying online in rural areas. Moreover, responses were transcribed and analyzed through thematic analysis. The participants of the study were seven language learners, two males and five females who study online in rural areas. It was discovered from the interviews that among the challenges encountered are problems with internet connectivity, lack of comprehensive discussion of lessons, less interaction among peers/classmates, rare opportunity to enhance speaking skills, and absence of feedback mechanism. It was also found that students' coping mechanisms include relocating to places known to have a greater internet access, disregarding public distractions, studying independently, reserving battery, and asking support from peers.

Published by Al-Kindi Center for Research and Development, London, United Kingdom. Copyright (c) the author(s). This open access article is distributed under a Creative Commons Attribution (CC-BY) 4.0 license (https://creativecommons.org/licenses/by-nc$n d / 4.0 /)$

\section{Introduction}

A necessary adaptability to the "new normal" way of life transpired as the regular function of various activities around the world has been disrupted due to the unforeseen outbreak of COVID-19. Unfortunately, education is no exception. For the continuous delivery of instruction to be possible despite the pandemic, educators were forced to shift from face-to-face instruction to virtual classrooms (Cao, Dong, \& Li, 2020). This means that because of the need to implement new ways of teaching, the traditional classroom is no longer permissible. Thus, both the teachers and the students had to leave the four corners of the classroom and embrace the newly induced online learning platform.

In this sense, the ability of students to be adaptive with the drastic changes in the educational field has been tested, language learners in rural areas in particular. While the shift to virtual learning was unescapable, many learners in rural areas are challenged James (2001) as they are unable to access online resources due to the lack of infrastructure, the unavailability of electricity and technological resources, and the limited internet connection which are all vital in the newly implemented platform (Dube, 2020). For this reason, it appears that virtual learning makes the urban learners more privileged and the rural learners more deprived of the necessary learning resources. In fact, Reddy and Ramesh (2020) also affirmed that the limited internet connectivity and technological tools has become a major problem for students who study online in rural areas. These findings suggest that while online-based learning serves as the only practicable alternative to face-to-face instruction, this mode unfortunately excludes many learners in rural areas. Thus, although Bellias et al. (2013) stated that virtual learning proposes a new manner of presenting the content of education effectively, many students even have to struggle with challenges associated to their area's rurality (Alderson, Barnes, Douglas, Flittner, \& Kilpatrick, 2018).

With an aim to suggest solutions to the existing problem, numerous researchers have tried to carefully and critically analyze the coping mechanisms used by students studying online in rural areas. For instance, in the Philippine context, Custodio, a freshman student who attends online classes using her 5 -inch screen cellphone copes with the challenge by downloading the lessons on 
her phone and re-writing them to better grasp the content when reading Santos (2020, as cited in Cahapay and Rotas, 2021). Such a coping mechanism may be used for students who struggle with the insufficient technological resources such as an android phone, a netbook, a laptop, or a computer. In a similar vein, a study conducted by Baloran (2020) revealed that Filipino students copes up with online learning struggles by maintaining a strong bond and attachment with friends and family to relieve stress as well as encouraging oneself to increase motivation. Inarguably, such a coping strategy can sustain students' emotional health which is helpful in the quest for academic success. In addition, these findings imply that regardless of the challenges, students still urge to survive online-based learning by means of different coping mechanisms. Considering education as a global common good United Nations (2020), learners' outlook, responses, and actions constantly appear to be positive despite the many struggles they encounter.

In the light of these findings, it can be deduced that virtual learning can be very problematic to a large number of tertiary students studying online in rural areas as proven by the many researchers in their previous investigations. Other researchers also tried to delve into the coping mechanisms used by these students to somehow remedy their struggles. However, the search for literature indicates that there has been very limited discussion in studies concerning language learners. Interestingly, this study gives an account to the challenges and coping mechanisms of language major students in particular. In addition, this paper tries to argue that while COVID-19 has made online-based learning a practicable alternative to the face-to-face instruction, there is a need to investigate the lived realities of rural language learners considering the fact that majority of the students in rural areas struggle with geographical limitations (Cheng, Lin \& Liu, 2007). In this case, it is essential to investigate language learners' challenges and coping mechanisms in virtual learning in order to provide learners the adequate and sufficient support they need. Otherwise, students will more likely withdraw from their course (Gamie et al. 2002).

Hence, this study intended to determine the challenges and coping mechanisms of language learners studying online in rural areas in order to determine problems and suggest solutions to an existing problem that is not largely explored when viewed in the context of tertiary students taking language courses. Furthermore, the paper aimed to provide essential information and formulate useful recommendations needed for future investigations.

\subsection{Research Problems}

The present study aimed to determine the challenges and coping mechanisms of language learners studying online in rural areas. Specifically, the investigation sought to answer the following questions:

1. What are the challenges faced by language learners studying online in rural areas?

2. How do the language learners cope with the challenges of language learning performed online?

\section{Review of Related Literature}

\subsection{Online-based Learning}

The world has been brought to comfort and accessibility as different technologies continue to advance. With the notable progress in its development in this ever-changing and globalized society, it has even made the shift from face-to-face instruction to online-based learning possible. In light of this, Singh and Thurman (2019), defined online learning as an educational experience that requires the utilization of technological devices where students interact with teachers and other students in either synchronous or asynchronous virtual class. Similarly, Fry (2001) described it as a learning experience that makes use of the internet and other important technologies to produce materials for the teaching and learning process. In other words, it refers to a virtual learning experience that requires a great deal of technological tools and internet access in order to deliver innovative and well-designed teaching modalities for students' learning. Inarguably, the utilization of the internet has provided unprecedented opportunities for many learners (Erarslan \& Topkaya, 2017).

In this regard, the incorporation of technologies in language education has been a subject of contradicting opinions in the field or research especially when the case of language learners who study online in rural areas is taken into consideration. In terms of the benefits relating to technological skills and performance, Weiner (2003) found that virtual classroom is helpful in improving students' technological skills. However, Flye, Gibson, Seemann, and Wilkinson (2002, as cited in Appanna, 2008) rejected his claim, asserting that many students in different schools who study online in rural areas do not have computers at home or in their community. This means that although online education serves as an avenue to improve students' technological skills, not all students are afforded with the needed access to benefit from the program. Other contradicting claims include that of Smedley (2010) and Taylor (2002). The former concluded that online learning is of great advantage because students are afforded with much flexibility of time and place. The latter opposed by raising a concern that in any given time or place; technical problems may occur which can make videoconferencing and virtual meetings troublesome in some struggle from limited internet connectivity (James, 2001). Thus, even though it is more comfortable to work at home, technological problems remain to be uncontrollable especially in the case of rural learners. Hence, online-based learning when viewed in the context of language learners in rural areas captures a more challenging experience. 


\subsection{Challenges in Online-based Learning}

Virtual learning in higher education courses are known to have higher attrition rates than face to face instruction (Angelino, Natvig, \& Williams, 2007). Study shows that while students are initially drawn to online learning because of its convenience and flexibility, there are a number of challenges that students had to face later. For example, Choi and Lee (2011) stated that one of these challenges may be related to issues with technology of which they claimed that problems may arise when students are not technologically competent as they may find difficulties in navigating their way through the online content. Similarly, Ramanujam (2002 as cited in Rao, Eady \& Edelen-Smith, 2011) maintained that the lack of technology skills is a commonly cited challenge faced by learners in rural areas apart from the slow internet connectivity. This means that since online learning necessitates the use of technologies, students must be adept in manipulating digital resources. Otherwise, it will impose difficulties. The situation can even be more problematic if students are not afforded with these resources. Flye, Gibson, Seemann, and Wilkinson (2002 as cited in Appanna, 2008) have asserted that in rural areas, the lack of technological resources appears to be one of the most commonly faced challenges.

Another seen challenge is its non-interactive learning process. Although technology is known for its ability to connect people, in online learning, it is frequently used in a non-interactive manner. This is demonstrated by teachers who provide content via ereadings or a static online lecture. Unfortunately, it also leads to lack of feedback or communication between teachers and students. This means that since there is no face-to-face contact in online learning, students may struggle with self-evaluation. The separation of student and teacher created by distance, according to Keegan (1986), removes a critical "link" of communication between distance learners and their lecture.

\subsection{Coping Mechanisms in Online-based Learning}

Online based learning poses a number of hurdles to learners but also leaves them with no other option but to overcome these challenges by employing different coping mechanisms. Because a solid internet connection is essential but is a major challenge in rural areas, learners manage by seeking out good space and time. Finding a better location for the wireless router, according to Cook (2019, as cited in Cahapay and Rotas, 2021) will help you get a better broadband connection. It is even worth noting that using Wi-Fi at night can help you avoid Wi-Fi traffic because there are less individuals fighting for air space. These are some of the techniques that students employ to gain a better internet connectivity and continue online schooling. Others might even have to move from home to an area with better internet connection. This is in keeping with the findings of Matswetu et al. (2020) of which they found that pupils who do not have an internet connection will look for every conceivable option to meet their needs.

Students can also cope with remote learning by borrowing educational materials. Because course assignments necessitate the use of laptop computers, a frequent coping method is to seek assistance from family members and other relatives who can aid as soon as possible Osafo $(2017$, as cited in Cahapay and Rotas, 2021) as the lack of technological resources appears to be one of the most commonly faced challenges of students in rural areas (Flye, Gibson, Seemann, and Wilkinson, 2002 as cited in Appanna, 2008). Another coping approach is to seek out peer assistance. According to Gore et al. (2014), students who are stressed because of a remote learning program often seek social support from their peers. This is in line with the claim of Wang (2000) of which he asserted that pupils form strong bonds to overcome feelings of loneliness.

Additionally, one strategy to deal with large amounts of instructional activities is to approach the teachers. This could be attributable to a successful online support system as part of an institution's e-learning program which is aimed at allowing students to connect with their lecturers about subject concerns (Talbot, 2007). Hence, the teacher's willingness to entertain students' concerns is highly essential as it appears to be beneficial for learners who struggle academically.

\section{Methodology}

\subsection{Research Design}

The primary purpose of the current study is to determine the challenges and coping mechanisms of language learners studying online in rural areas. Since the study aims to explore and analyze in word for word details the respondents' thoughts and experiences through prolonged dialogues, qualitative research design was employed. Hence, it offers an understanding of specific situation by analyzing phenomena that relay stories about experiences Denzin and Lincoln (1994, as cited in Alieto, Buslon, \& Devanadera, 2019). This implies that since qualitative research design reveals meaningful facets of human experiences and the aim of the current study is to understand students' challenges and coping mechanisms, it is considered as the most appropriate method to use. As contended by Huang (2015), qualitative interviews' purpose is to elicit in-depth answers from the respondents' experiences and probe questions in accordance with the research interest. Major and Savin-Baden (2010, as cited in Blackmon \& Major, 2012) also stated that this method is an essential tool for multiple reasons as it permits participants to relay stories about their experiences and allows the researcher to extract full responses.

\subsection{Participants of the study}


The investigation constituted 7 language learners (5 females, 2 males) studying online in rural areas across different institutions and universities in Zamboanga city with ages ranging from 20-22. The selection of participants was determined through the employment of purposive sampling technique to select respondents with particular characteristics following the needs of the investigation (Campbell et al., 2010). This means that respondents who are most likely to provide appropriate and useful information were selected to take part on the study. That being said, the following inclusion criteria were established to carefully and purposively select the participants of the study: (1) the respondent must be a language major student who is part of the present online-based educational system, and (2) the respondent must be studying online in a rural area. Otherwise, he/she cannot be qualified to take part in the data gathering procedure.

\subsection{Research Tool}

To determine the challenges and coping mechanisms of language learners studying online in rural areas, a qualitative approach was employed through a semi-structured interview via phone call. According to Jamshed (2014) semi-structured interviews as those in-depth interviews wherein the respondents need to answer questions that are exploratory and not restricted to one specific response. Since this study aims to investigate the respondents' actual experiences and thoughts through prolonged dialogues, respondents were asked to answer open-ended questions to gather data relevant to the aims of the study. The interview consisted three (3) questions. The first two questions solicited the challenges faced by language learners and while the last question determined the coping mechanisms employed these learners.

\subsection{Data Gathering Procedure}

After the development of interview questions, consent letters were sent to the participants via messenger informing them about the current investigation and seeking their consent for participation. Participants who agreed to take part in the research venture were scheduled for a semi-structured interview via phone call and the data gathering followed through audio recording of interviews. Consequently, a transcript was made for all gathered responses and were subjected to analysis. Moreover, the transcripts of the responses were transferred to Microsoft Excel for the analysis and interpretation of results. In so doing, the researcher developed themes based on the respondents' challenges and coping mechanisms that are pertinent to the research questions.

\subsection{Method of Analysis}

Thematic analysis was employed to examine the data of the current study. This is an effective technique to use when analyzing different perspectives of the respondents and in developing insights (Clarke, 2006; King, 2004 as cited in Moules, Norris, Nowell \& White, 2017). Hence, it is a form of analysis that deals with qualitative data. Before interpreting and analyzing the information collected, the data were first sorted and reviewed for commonality, a process known as thematic analysis. The main themes developed from the data particularly with regards to the respondents' challenges and coping mechanisms were categorized based on the recurring patterns identified.

\section{Results and Discussion}

This section presents the results of data analysis as regards the two research questions about the challenges and coping mechanisms faced by language learners studying online in rural areas. Common responses from the respondents are presented through themes and excerpts, followed by a brief description of the findings.

Table 1: Challenges in Online-based learning 


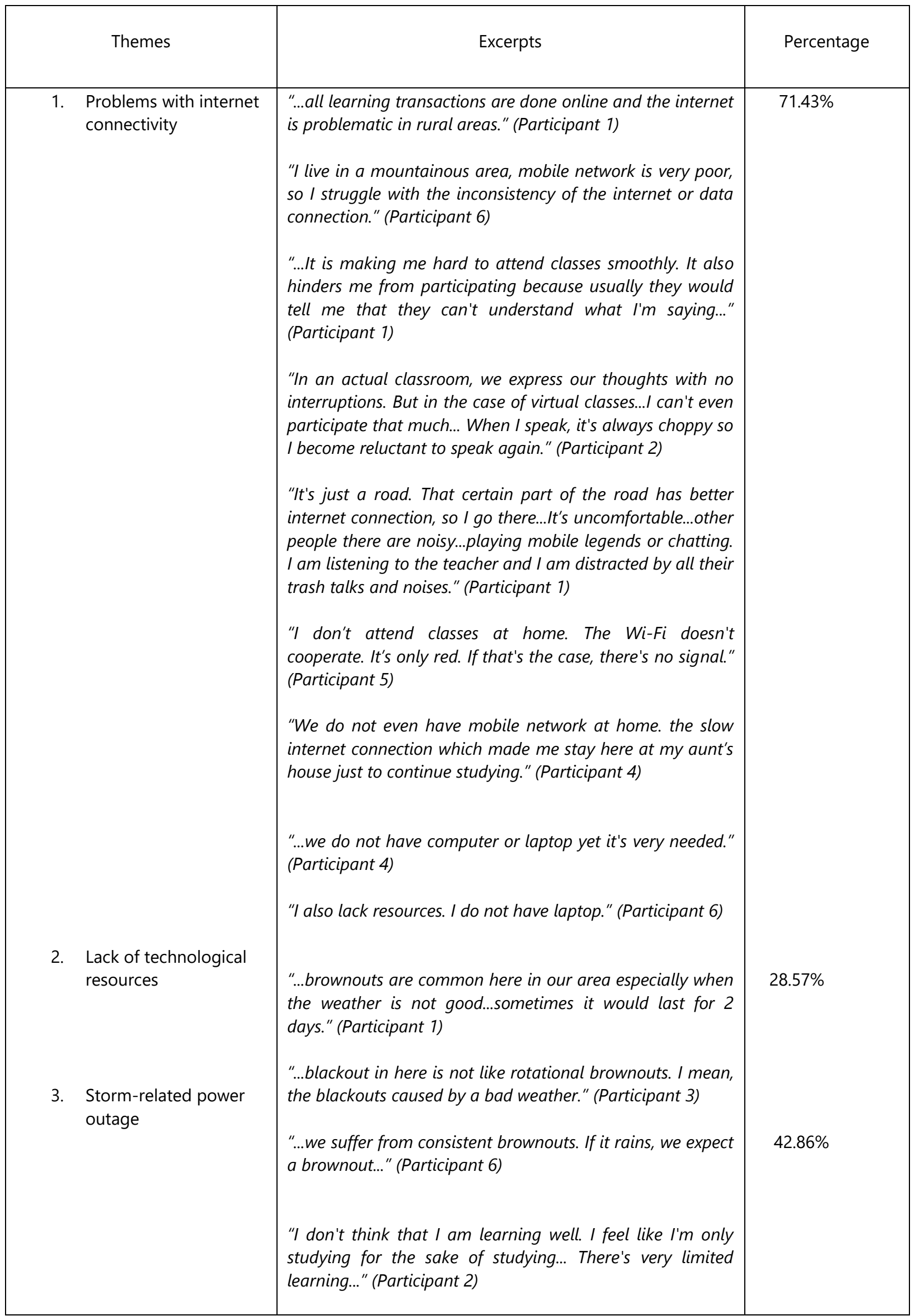




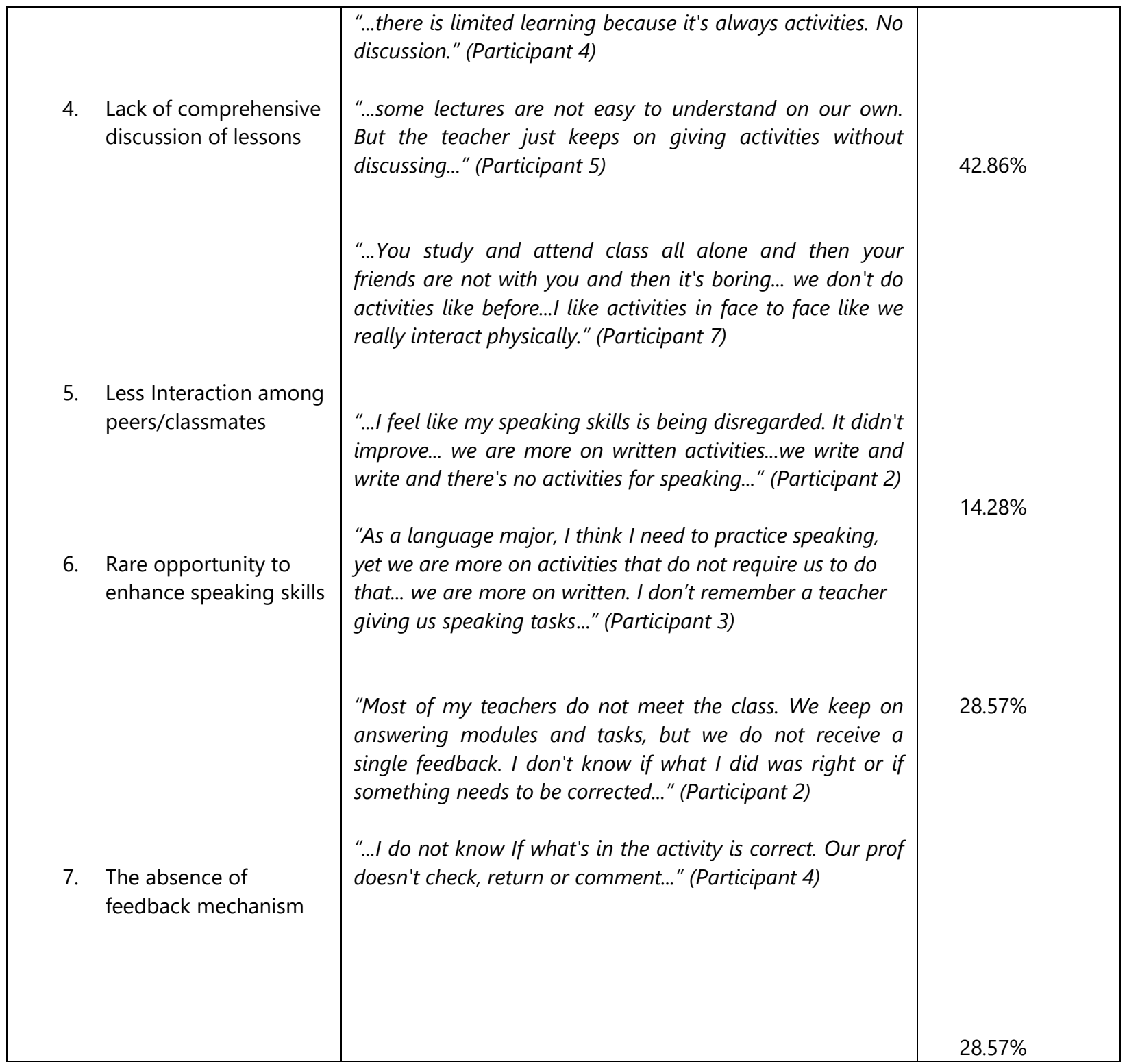

Table 1 shows the challenges of the respondents in online-based learning. There are seven themes which are presented.

\section{Problems with internet connectivity}

As emerged from the responses, five out of seven or $71.43 \%$ of the respondents experience limited inte rnet connection.

Below is one of the excerpts pointing to this idea:

\section{Participant 6}

I live in a mountainous area and mobile network is very poor, so I struggle with the inconsistency of the internet or data connection

This only implies that the slow internet connectivity greatly affects the conduct of online learning especially in the case of rural learners where internet connectivity is the poorest. In connection to this, Martinez and Esparcia (2020) explained that a noticeable internet connection shortfall is caused by orography which leads to a poor territory coverage. Moreover, $d$ ue to the slow internet connectivity, respondents expressed that they are even challenged in terms of class participations as two out of seven or $28.57 \%$ of the respondents explained that online learning in a rural area limits the opportunity to participate in virtual classes smoothly. 
The following excerpts are presented as evidence:

\section{Participant 1}

...It is making me hard to attend classes smoothly.

It also hinders me from participating because

usually they would tell me that they can't

understand what I'm saying...

\section{Participant 2}

In an actual classroom, we express our thoughts with no interruptions.

But in the case of virtual classes... I can't even participate that much...

When I speak, it's always choppy so I become reluctant to speak again.

Akamai (2011, as cited in Tria, 2020) stated that Philippines is reported to have the slowest internet connection in Asia. However, since the context of the study particularly deals with language learners in rural areas, internet connectivity appears to be more problematic. Moreover, participant 1 asserted that because of the slow internet connectivity, it leaves learners in rural areas with no option but to endure studying in an unconducive study area.

Below is the excerpt:

\section{Participant 1}

"It's just a road. That certain part of the road has better internet connection so I go there...It's uncomfortable... other people there are noisy...playing mobile legends or chatting. I am listening to the teacher and I am distracted by all their trash talks and noises."

Additionally, participant 4 stated that because of the very limited internet access at home, she had to stay in her aunt's house to attend classes. Such findings indicate that the slow internet connectivity appears to be a major challenge experienced by online language learners. In fact, it is the most frequent theme in the data. Because of this, smooth communication is hampered, and students had to move to an unconducive study area or stay in a relative's house to pursue online schooling.

\section{Lack of technological resources}

Participants are also faced with the lack of technological resources as two out of seven or $28.57 \%$ of the respondents remarked that they have limited digital resources which are deemed essential in online classes. This holds true with the idea of Flye, Gibson, Seemann, and Wilkinson (2002, as cited in Appanna, 2008) that many students in different schools, considering their area's rurality do not have computers at home or in their community. This means that although online education serves as an avenue to improve students' technological skills, it is necessary for all students, especially the ones in rural areas to be afforded with the needed access before they can benefit from the program. Otherwise, they will be left behind.

\section{Storm-related power outage}

Moreover, three out of seven or $42.86 \%$ of the respondents asserted that storm related power outage has been one of the challenges in virtual learning.

The excerpt below is pointing to this idea:

\section{Participant 1:}

brownouts are common here in our area especially when the weather is not good...sometimes it would last for days.

This may be true as Hasenburg (2009) explained that learning through the utilization of internet is challenging because of technical problems are uncontrollable which hampers the flow of online communication. Similar to the findings of the study, the power outage can potentially hinder students from attending virtual classes.

\section{Lack of comprehensive discussion of lessons}


It also yielded from the result that three out of seven or $42.86 \%$ of the respondents claimed that online learning is more on completion of tasks and not discussion of subject matter. This finding is explained by Fullerton, Taylor and Watson (2009) that online learning lessens demand of teacher-student interaction. As a result, it limits the teachers' direct guidance to students. Eventually, learners might be left with series of activities with no discussion of the subject matter. Additionally, participant 4 claimed that such a case leads to limited learning.

Below is the excerpt:

\title{
Participant 4
}

... and also, there is limited learning because it's always activities. No discussion.

Hence, it can be noted that there are professors who rarely discuss or do not discuss the lessons at all. Perhaps, some professors are still adjusting to the new norm in the educational scheme considering the claim of Lai and Kristonis (2016) that teachers of today do not have technological knowledge and are reluctant to accept the concept of online learning (Islam, Chowdhury \& Islam, 2009). In fact, in the investigation of Farmer (2019) entitled Exploring the Concerns of K-12 Teacher, he found that the insufficiency of necessary training for most online instructors can hamper meaningful teaching. This suggests that due to the lack of preparedness in utilizing advanced technologies, online-based learning becomes unfavorable for some teachers. Unfortunately, this also becomes a challenge for students as it causes the lack of comprehensive discussion of lessons which is deemed essential for learners who, in an online set-up are mostly given a pile of activities to comply.

\section{Less interaction among peers/classmates}

One respondent emphasized that the less interaction among peers/classmates causes boredom in online learning. Inarguably, students can learn better when they are given the opportunity to have a meaningful interaction with their environment (Duncan, Hudson, \& Range, 2013). This further means that the absence of physical contact with classmates withdraws student interest in learning. Alarmingly, lack of learning atmosphere and social interaction among the learners can cause inactiveness and may result in poor learning outcomes (Dong et al. 2020).

\section{Rare opportunity to enhance students' speaking skills}

two out of seven or $28.57 \%$ of the respondents also revealed that in online learning, there is a less opportunity to enhance students' speaking skills. The ground seen is that the newly induced platform requires learners to comply pile of purely written activities with little to no regard to speaking tasks.

The excerpt below is pointing to this idea:

\section{Participant 3}

\author{
As a language major, I think I need to practice speaking, \\ yet we are more on activities that do not require us to do that... \\ we are more on written. I don't remember a \\ teacher giving us speaking tasks...
}

Such findings indicate that the online learning set up have lessened the demand of speaking activities and apart from the cause stated, this may be attributed to other reasons. Findings in the current study shows that the limited internet connectivity hampers smooth flow of virtual communication which makes students reluctant to speak or participate in class discussions. For this reason, some learners are deprived to express their thoughts verbally, causing less practice for speaking. Apart from that, participant 2 shared that some of his teachers rarely meet the class but kept on giving pile of activities. This indicates that in some cases, even if a students' internet connectivity is good, without the presence of teacher, students are still deprived to practice speaking.

\section{The absence of feedback mechanism}

Lastly, two out of seven or $28.57 \%$ of the respondents expressed that the absence of feedback mechanism has been one of the challenges encountered in online-based learning. Since the newly induced platform causes less student-teacher interaction, teachers' feedback on students' activities is hampered. Particularly, participant 2 elaborated that most of his teachers are giving pile of tasks to accomplish. However, no feedback is given after submission which leaves him clueless as to whether he was 
answering the activities right or if something needs to be corrected. One reason is found in the study of Llimiani, Nugroho and Rekha (2021) where findings revealed that since preparing materials for online teaching is very time consuming, teachers do not have enough time to give evaluate and give feedback to students' tasks.

Table 2: Coping Mechanisms in Online-based learning

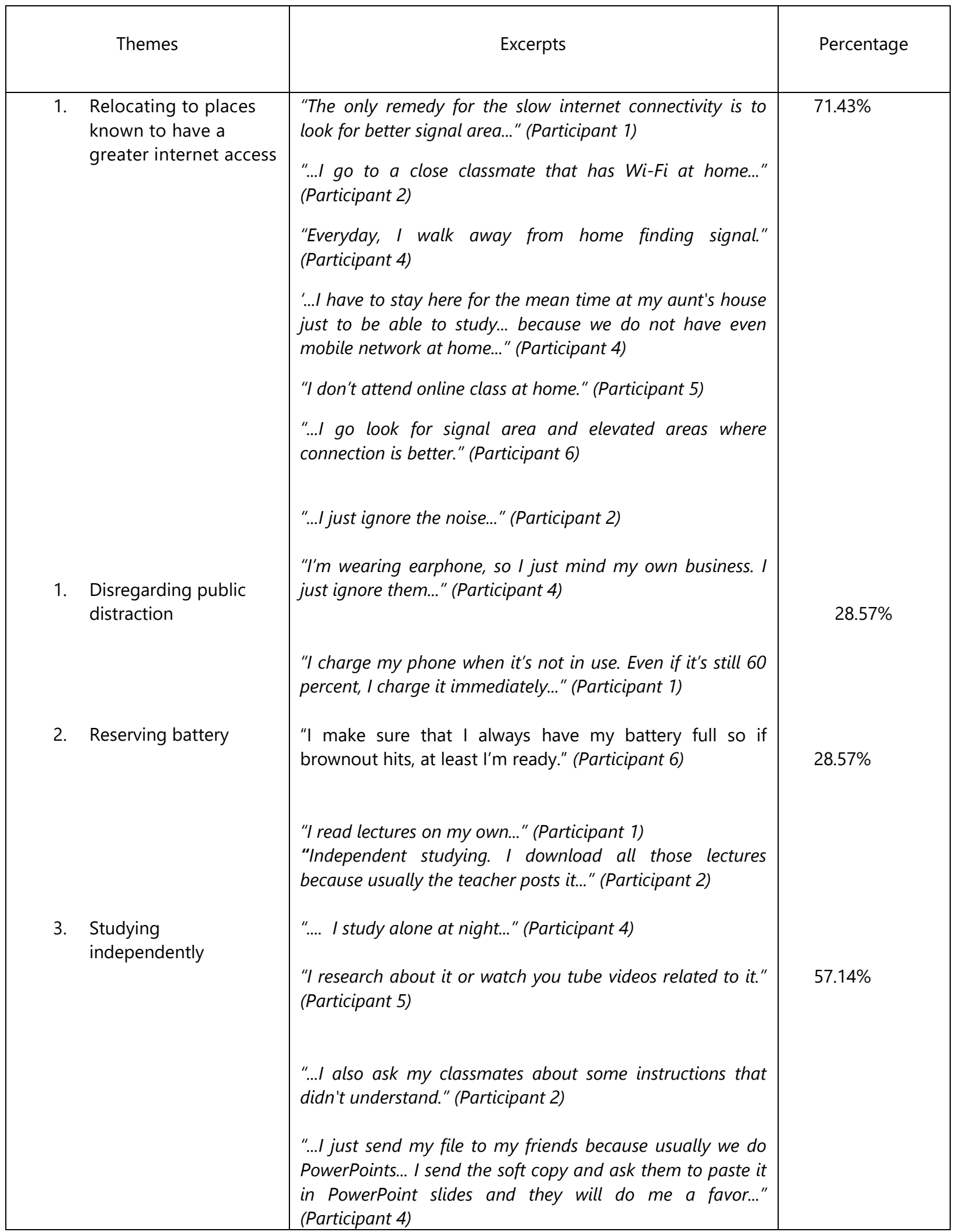




\begin{tabular}{|l|l|l|}
\hline $\begin{array}{l}\text { 4. Asking support from } \\
\text { peers }\end{array}$ & $\begin{array}{l}\text { "I ask help from my classmates... whenever I miss my } \\
\text { classes, they help me in terms of notes and assignments, } \\
\text { and when I have questions about the lesson, they teach me } \\
\text { through texting and even calling if my connection is } \\
\text { stable." (Participant 6) }\end{array}$ \\
$\begin{array}{l}\text { "... know that I can still ask them whenever I have } \\
\text { questions about something like tasks." (Participant 7) }\end{array}$ & $57.14 \%$ \\
\hline
\end{tabular}

Table 2 presents the coping mechanisms of language learners in online learning. The participants provided five ways on to cope up with the difficulties.

\title{
Relocating to places known to have a greater internet access
}

Five out of seven or $71.43 \%$ of the respondents noted that in terms of limited internet connectivity, looking for a space which means moving to an area with better connection has been the only remedy to overcome the challenge. In fact, participants narrated experiences of having to walk away from home, go to a classmate, or stay in a relative's house in order to attend classes online. Cook (2019, as cited in Cahapay and Rotas, 2021) opined that because a stable internet connection is essential but is a major challenge in rural areas, learners manage by seeking out good space and time. This implies that despite the challenge, students manage to exert effort in moving from one place to another just to continue learning online. According to participant 5 , the experience is not easy. She stated that to be able to attend classes, she must travel everyday from home to her uncle's house.

Below is the excerpt:

\section{Participant 5}

\author{
...it's difficult because I travel everyday and on some days, \\ the weather is not good, and it keeps on raining \\ so we get rained on.
}

This indicates that despite being faced with such a challenge, respondents seem to show a positive attitude in dealing with adversities. In fact, participant 5 elaborated that when she arrives home and she feels exhausted from the long travel, she would drink coffee and grab some rest and she would feel better. Participant 6 also shared that although she has been having a hard time in getting a stable internet access, she understands that she has to be more responsible, and she reiterated that taking more responsibility includes having patience in moving to an area known to have a better internet connectivity if situation demands.

\section{Disregarding public distractions}

Moreover, ignoring distractions appeared to be a scoping mechanism employed to deal with unconducive study areas as articulated by two out of seven or $28.57 \%$ of the respondents.

The excerpt below is pointing to this idea:

\section{Participant 2}

$$
\text { ...l just ignore the noise... }
$$

These suggest that learners who had to move to a distracting study area in order to attend virtual classes overcome the challenge by focusing on their academic activities instead of paying attention to any form of distraction. Previously, it was reported that because of the limited internet connectivity at home, learners had to move to an unconducive study area where distractions are inevitable. Participant 4 shared that since her study area is a typical road, the situation will sometimes demand her to run to a store nearby especially if it rains. However, she also stated that noises cannot be avoided but wearing an earphone helps her ignore the noise and focus on academic-related activities. Hence, concentration can help learning take place despite how busy the environment is and since public noises are inescapable, learners' last resort is to ignore distractions. 
In terms of the storm-related power outage, 2 out of seven or $28.57 \%$ of the respondents articulated that reserving battery is an effective strategy to secure that online learning devices are kept charged. This suggests that since online learning necessitates the use mobile phones, laptop, netbook, iPod, and other technological devices, learners assume power outage in advance and make sure that their digital devices are fully charged before then. Although it was reported that storm-related power outage is a major challenge in rural areas, it seems that learners are always prepared by reserving battery as they consider the need for their devices to be fully charged at all times.

\section{Studying independently}

Independent learning was also found as learners' coping mechanism in the lack of comprehensive discussion of lessons as expressed by four out of seven or $57.14 \%$ respondents. For example, participant 2 stated that when she fails to fully understand a certain lesson, reading lectures on her own greatly helps. Similarly, participant four shared that in such a case, she studies alone at night. Additionally, participant five responded saying that she watches YouTube videos related to the lesson. All these coping mechanisms revolve around one common strategy which is independent learning. This finding is supported by Boekaerts (1997) who stated that those who know how to work independently are active and not passive learners. These students can take responsible actions and make appropriate decisions when academic problems arise. In turn, these independent learning skills may serve as an effective means to succeed in several challenges faced in tertiary education.

\section{Asking support from peers}

Lastly, four out of seven or $57.14 \%$ of the respondents believed that peer support system effectively helps in some challenges encountered. Participant 2 stated that when limited internet connection interrupts the smooth flow of virtual communication, he asks his classmates about certain instructions that he failed to understand. Likewise, participant 6 articulated that communicating with her classmates to ask for a copy of missed lectures has been her way of catching up with interrupted discussions. In addition, participant 7 also shared that whenever she is faced with some academically related concerns, she is certain that her classmates would help at clarifying her concern. Interestingly, problems as regards the lack of technological resources was found to be remedied utilizing the same coping mechanism as participant four stated "I just send my file to my friends because usually we do PowerPoints... I send the soft copy and ask them to paste it in PowerPoint slides and they will do me a favor..." This means that distance cannot stop strategic learners from helping each other as it is evident from the responses that students see the benefit of asking help from their classmates. Weller (2002) as stated in Croft, Dalton, and Grant (2010) affirmed this by stating that if the internet is utilized as a communication tool, then collaborative learning mode should only be promoted well.

\section{Conclusion}

The current investigation tried to determine the challenges faced by language learners studying online in rural areas. Evidently, the research data shows that respondents are challenged in various ways. However, challenges are found to be remedied utilizing different coping strategies by the strategic language learners. Based on the data presented in the study, the following conclusions are constructed.

It can be noted that the challenges that language learners experience in their virtual learning are problems with internet connectivity, lack of comprehensive discussion of lessons, less interaction among peers/classmates, rare opportunity to enhance speaking skills, and absence of feedback mechanism. Moreover, students' coping mechanisms include relocating to places known to have a greater internet access, disregarding public distractions, studying independently, reserving battery, and asking support from peers.

Furthermore, this study found that the most occurring problem in virtual learning of language is the internet connectivity problem, whereas five out of the seven or $71.43 \%$ of the respondents expressed the same concern. On the other hand, the frequently used coping mechanism is relocating to places known to have a greater internet connectivity as five out of seven or $71.43 \%$ of the respondents shared the same strategy.

\section{Implications}

It can be deduced that the physical separation of students and teachers, as well as the necessity for a stable internet access appear to be the most prevailing challenges faced by learners in online-based learning. Due to the absence of formal instruction, students are forced to learn independently, and majority are challenged because there has been very limited discussion of lessons, yet pile of activities are given to accomplish with no feedback provided after submission. Additionally, the slow internet connectivity also hampers leaning in many ways. Hence, due to the challenges identified in this study, it is possible that onlinebased learning has not been truly an effective platform for students who are faced with the same challenges. In light of this, there must be an obligation on the part of the institutions to provide teachers a training for online teaching tools and tactics so that they can enhance their knowledge, skills and comprehension of the various features and intricacies of online learning. Similarly, the government must also address and solve long-standing problems with internet connectivity to minimize interruptions in virtual learning. 
When faced with the abovementioned challenges, the respondents employed a variety of coping mechanisms to deal with them. Clearly, findings of this study demonstrate that students should always find remedies to learn best despite the challenges and constraints that online-based learning presents.

\section{References}

[1] Dong, C., Cao, S. \& Li, H. . (2020). Young children's online learning during COVID-19 pandemic: Chinese. Children and Youth Services Review.

[2] Alderson, R., Barnes, k., Douglas, J., Flittner, N., \& Kilpatrick, S. (2018). Embedding tertiary education in rural communities: Building 'warm connections'. Studies in Continuing Education, 1-15.

[3] Alieto, E., Buslon, J., \& Devanadera, A. (2019). Women of K-12: Exploring teachers' cognition in language policy implementation. The Asian EFL Journal, 24(4.1), 110-362.

[4] Angelino, LM., Williams, F.K., \& Natvig D. (2007). Strategies to engage online students and reduce attrition rates. J. Educ Online, 4(2), 1-4.

[5] Appana, S. (2008). A review of benefits and limitations of online learning in the context of the student, the instructor and the tenured faculty. International Journal on E-learning, 7(1), 5-22.

[6] Baloran, E. (2020). Knowledge, attitudes, anxiety, and coping strategies of students during COVID-19 pandemic. Journal of Loss and Trauma, 25(8), 1-8.

[7] Bellias, D., Sdrolias, L., Kakkos, N., Kautiva, M. \& Koustelios, A. (2013). Traditional teaching method vs teaching through application of information and communication technologies in accounting field: quo vadis. European Scientific Journal, 9(28), 73-10.

[8] Blackmon, S. \& Major, C. (2012). Students experiences in online courses: A qualitative research synthesis. The Quarterly review of Distance Education, 13(2), 77-85.

[9] Boekaerts, M. (1997). Self-regulated learning: A new concept embraced by researchers, policy makers, educators, teachers and students. Learning and Instruction, 7(2), 161-186.

[10] Campbell, S., Greenwood, M., Prior, S., Shearer, T., Walkem, K., Young, S., Bywaters, D., \& Walker, K. . (2020). Purposive sampling: Complex or simple? Research case examples. Journal of Research in Nursing, O(0), 1-10.

[11] Cao, S., Dong, C., \& Li, H. . (2020). Young children's online learning during COVID-19 pandemic: Chinese. Children and Youth Services Review.

[12] Cheng, S., Lin, C., \& Liu, E. (2007). Learning with online tutoring: Rural area students' perception of satisfaction with synchronous learning. International Journal of Computers, Communications \& Control, 36-42.

[13] Croft, N., Dalton, A., \& Grant, M. (2010). Overcoming isolation in distance learning: building a learning community through time and space. Journal for Education in Built Environment, 5(1), 27-64.

[14] Dube, B. (2020). Rural online learning in the context of COVID-19 in South Africa: Evoking an inclusive education approach. Multidisciplinary Journal of Educational Research, 10(2), 135-157.

[15] Duncan, H. E., Hudson, M., \& Range, B. . (2013). Exploring students' perception on rigor Online: towards a definition of rigorous learning. Journal on Excellence in College Teaching, 24(4), 5-28.

[16] Fry, K. (2001). E-learning markets and providers: Some issues and prospects. Education Training, 233-239.

[17] Fullerton, S., Taylor, D., \& Watson, J. . (2009). Web-based instruction \& online delivery of classes: Where are we now? American Journal of Business Education, 2(1), 91-100.

[18] Gammie, E., Gammie, B., \& Duncan, F. (2002). Operating a distance learning module within an undergraduate work placement: Some reflections. Education and Training, 44(1), 11-22.

[19] Hassenburg, A. (2009). Distance education versus the traditional classroom. Berkeley Scientific Journal, 13(1), 7-10.

[20] Huang, D. (2015). Exploring and assessing effectiveness of English medium instruction courses: The students' perspectives. Procedia Social and Behavioral Sciences, 173, 71-78.

[21] Islam, S., Chowdhury, S., \& Islam, A. . (2009). Lix education in e-learning environment: Problems and proposal for Bangladesh. Asia Pacific Conference on Library \& Information Education \& Practice, 519-529.

[22] James, R. (2001). Partcipation disadvantage in Australian higher education in mid-life: A life course agency perspective. Journal of Adult and Continuing Education, 42(4), 455-472.

[23] Jamshed, S. (2014). Qualitative research method-interviewing and observation. Journal of Basic and Clinical Pharmacy, 5(4), 87-88.

[24] Lai, C.C., \& Kritsonis, W. . (2006). The advantages and disadvantages of computer technology in second language acquisition. Doctoral Forum National Journal for Publishing and Mentoring Student Research, 3(11), 1-5.

[25] Lee, J.S. \& Choi, C.Y. (2011). Examining the law of educational and functional values in festival evaluation. Journal of travel.

[26] Martinrz, I.R \& Esparcia, J. (2020). Internet access in rural areas: brake or stimulus as post COVID-19 opportunity? Sustainability, 12(0), 1-17.

[27] Matswetu, V. S., Munakandafa, W., Munodawafa, V. \& Mandoga, E. (2020). Science student teachers' challenges and coping strategies in an open and distance learning environment in Zimbabwe. Makarere Journal of Higher Education, 4(2), 125-137.

[28] Moules, N., Norris, J., Nowell, L., \& White, D. . (2017). Thematic analysis striving to meet trustworthiness criteria. International Journal of Qualitative Method, 6(0), 1-13.

[29] Nations, U. (2020). Policy brief: Education during COVID-19 and beyond. Retrieved from https://www.un.org/development/desa/dspd/wpcontent/uploads/sites/22/2020/08/sg_policy_brief_covid19_and_education_august_2020.pdf

[30] Nugroho, A., Rekha, A., \& Llimiani, D. (2021). EFL teachers' challenges and insights of online teaching amidst global pandemic. Metathesis of Journal of English Language Literature and Teaching, 4(3), 277-291.

[31] Rao, K., Eady, M., \& Edelen-Smith, P. . (2011). Creating virtual classrooms for rural and remote communities. Phi Delta Kappan, 92(6), $22-27$.

[32] Reddy, D.S. \& Ramesh. L. (2020). Pros and cons of e-learning by children in rural areas during lockdown situation and ways to empower it. International Journal of Innovative Technology and Research(2320-5547), 7-8. 
[33] Rotas, E. \& Cahapay, M. (2021). From stress to success: Exploring how Filipino students cope with remote learning amid COVID-19 pandemic. Journal of Pedagogical Sociology and Psychology, 3(1), 27-35.

[34] Singh, V., \& Thurman, A. . (2019). How many ways can we define online learning? A systematic literature review of definitions of online learning. American Journal of Distance Education, 33(4), 289-306.

[35] Smedley, J. (2010). Modeling the impact of knowledge management using technology or insight. (23), 230-250.

[36] Talbot, J. (2007). Delivering distance education for modern government: The F4Gov programme. Journal of education and Training, 49(3), 250-60.

[37] Taylor, R. (2002). Pros and cons of online learning - A faculty perspective. Journal of European Industrial Training, 26(1), 24-37.

[38] Topkaya, E.Z., \& Erarslan, A. . (2017). EFL students' Attitudes towards e-learning and effect on an online course on students' success in English. The Literacy Trek, 3(2), 80-101.

[39] Tria, J. (2020). The covid -19 pandemic through the lens of education in the Phillippines: The new normal. International Journal on Pedagogical Development and Lifelong Learning, 1(1), 1-2.

[40] Wang, H. (2005). A qualitative exploration of the social interaction in an online learning community. International Journal of Technology in teaching and Learning, 1(2), 79-88.

[41] Weiner, C. (2003). Key ingredients to online learning: Adolescent student study in cyberspace - The nature of the study. International Journal on E-Learning, 2(3), 44-50. 